10. IOP Conf. Ser.: Earth Environ / A. I. Sukhareva [et al.] // Sci. 2021. V. 677. 032007.

11. IOP Conf. Ser.: Earth Environ / I. F. Gorlov [et al.] // Sci. 2020. 548082032.

12. Lovage (Levisticum officinale W.D.J. Koch) roots: A source of bioactive compounds towards a circular economy / R. M. Sprea R M [et al.] // Resources. 2020. V. 9 (9). P. 81.

\title{
Authors Information
}

Khramova Valentina, doctor of Biological Sciences, Professor, Dean of the faculty of food production technology, Volgograd State Technical University (28 V. I. Lenin Ave., Volgograd, 400005, Russian Federation). E-mail: hramova_vn@mail.ru

Anna Pimenova, student of the faculty of food production technology, Volgograd state technical University (28 V. I. Lenin Ave., Volgograd, 400005, Russian Federation).

E-mail: any.pimenova270499@yandex.ru

Khramova Yaroslavna Igorevna, graduate student of the Department of Industrial Ecology and Safety, Volgograd State technical University (28, Lenin avenue, Volgograd, 400005, Russia). E-mail: ftpp@vstu.ru Svetlana Bozhkova, candidate of Biological Sciences, Associate Professor of the Department of Food Production Technology, Volgograd State Technical University (28, V. I. Lenin Ave., Volgograd, 400005, Russian Federation). E-mail: bozhkova@mail.ru

\section{Информация об авторах}

Храмова Валентина Николаевна, доктор биологических наук, профессор, декан факультета технологии пищевых производств Волгоградского государственного технического университета (РФ, 400005, Волгоград, пр-т. им. В. И. Ленина, 28). E-mail: hramova_vn@mail.ru

Пименова Анна Михайловна, студент факультета технологии пищевых производств Волгоградского государственного технического университета (РФ, 400005, Волгоград, пр-т. им. В. И. Ленина, 28). E-mail: any.pimenova270499@yandex.ru

Храмова Ярославна Игоревна, аспирант кафедры промышленной экологии и безопасности жизнедеятельности, ФГБОУ ВО «Волгоградский государственный технический университет» (400005, Россия, г. Волгоград, пр-т. им. В. И. Ленина, 28). Е-mail: ftpp@vstu.ru

Божкова Светлана Евгеньевна, канд. биол. наук, доцент кафедры «Технология пищевых производств» Волгоградского государственного технического университета (РФ, 400005, Волгоград, пр-т. им. В. И. Ленина, 28). E-mail: bozhkova@mail.ru

\section{DOI: 10.32786/2071-9485-2021-02-31 THE EFFECTIVENESS OF THE USE OF FEED ADDITIVES IN THE FORMULATION OF COMPOUND FEEDS FOR POULTRY}

\author{
V. V. Shkalenko, A. K. Karapetyan, A. A. Baksarova, Yu. G. Bukaeva \\ Volgograd State Agrarian University, Volgograd
}

Received 13.04.2021

Submitted 10.06.2021

\section{Summary}

The article presents the results of using an organomineral supplement when it is introduced into compound feed for laying hens. At the research base of the Volgograd State Agrarian University, studies were carried out, during which it was found that the zootechnical and economic indicators in the poultry that participated in the experiment were normal. It should be noted that the best was the Iexperimental group, which was injected with an organomineral supplement in the amount of $4 \%$.

Abstract
Introduction. To provide the population with food with high-quality products in full, high-quality
livestock and poultry products are necessary [9]. This is achieved due to the balanced diet for birds.
Unfortunately, farms do not always have all the necessary minerals that are used to balance diets. In
this regard, various mineral mixtures should be used in such farms. The aim of the research was to
increase the egg production of poultry and the quality of eggs when using an organomineral supple-
ment in the diet of experimental laying hens [5]. Organomineral additive is a mud of sulfide-silt com-
position. It is formed at the bottom of reservoirs, which contain a huge amount of mineral salts [4].
The chemical composition of the organic additives on the basis of sulfide silt mud has the following
composition, \% of dry matter: dissolved salt of 6.67 and $15.44 \%$; gypsum $\left(\mathrm{CaSO}_{4}\right) 0,23-1,71 \%$; calci-


um carbonate $\left(\mathrm{CaSO}_{3}\right)$ of 7.31-of 11.23\%; magnesium carbonate $\left(\mathrm{MgCO}_{3}\right)$ of 1.86-12.61 per cent; iron sulfide (FeS), including $\mathrm{H}_{2} \mathrm{~S}$ 0,9-1,96\%; degradation products of $\mathrm{HCl}$, including $\mathrm{SiO}_{2}, \mathrm{Fe}_{2} \mathrm{O}_{3}, \mathrm{Al}_{2} \mathrm{O}_{3}$ $5,55-6,85 \%$. The object of the study. The object of research was laying hens. Materials and methods. Thus, an experiment was carried out on a hybrid cross-breed «Hysex Brown» bird at the Research Center for the Safety and Effectiveness of Feed and Additives of the Volgograd State Agrarian University. At the age of forty weeks, the experimental bird was selected and divided into three groups, the first was a control, the second and the third were experimental. The duration of the experiment was 20 weeks. Results and conclusions. With the inclusion of different doses of organomineral additives, 4 and $5 \%$ in the composition of the mixed feed of laying hens, the egg productivity increased by $2.84 \%$ and $1.35 \%$. It is worth noting that the number of eggs obtained from the birds of the experimental groups was greater and belonged to the selected and highest category. When introducing an organomineral supplement into the diets of laying hens, the economic effect ranged from 1075.44 rubles to 1696.92 rubles. In the course of our research, it was found that the organomineral supplement had a positive effect on both zootechnical and economic indicators. The optimality of the introduction of organomineral additives in the formula of compound feed for experimental poultry was $4 \%$. silt mud.

Key words: laying hens, organomineral additive, productivity, egg production, sulfide-

Citation. Skalenko V. V., Karapetyan A. K., Bakirova A. A., Bukaeva Yu. G. The effectiveness of the use of feed additives in the formulation of compound feeds for poultry. Proc. of the Lower Volga Agro-University Comp. 2021. 2(62). 298-305 (in Russian). DOI: 10.32786/2071-9485-2021-02-31.

Author's contribution. In this experiment, all the authors participated in the planning, execution,and analysis of the research results. The presented version of the article is approved by all the authors.

Conflict of interest. The authors did not declare a conflict of interest.

УДК 636.5.034.087.72

\section{ЭФФЕКТИВНОСТЬ ИСПОЛЬЗОВАНИЯ КОРМОВОЙ ДОБАВКИ В РЕЦЕПТУРЕ КОМБИКОРМОВ ДЛЯ СЕЛЬСКОХОЗЯЙСТВЕННОЙ ПТИЦЫ}

В. В. Шкаленко, доктор биологических наук, профессор

А. К. Карапетян, доктор сельскохозяйственных наук, доцент

А. А. Баксарова, аспирант, Ю. Г. Букаева, соискатель

Волгоградский государственный аграрный университет, г. Волгоград

Дата поступления в редакцию 13.04.2021

Дата принятия к печати 10.06.2021

Актуальность. Для обеспечения населения питанием качественной продукцией в полном объеме необходимы продукты животноводства и птицеводства высокого качества [7]. Достигается это за счет сбалансированности рациона для птиц. К сожалению, в хозяйствах не всегда имеются все необходимые минеральные вещества, которые применяют для балансировки рационов. В связи с этим в таких хозяйствах следует применять различные минеральные смеси. Цель исследования увеличить яйценоскость сельскохозяйственной птицы и качество яиц при использовании органоминеральной добавки в рационе подопытных кур-несушек [2]. Органоминеральная добавка - это грязь сульфидно-илового состава, которая образуется на дне водоемов. В ее составе находится огромное количество минеральных солей [5]. Химический состав органоминеральной добавки на основе сульфидно-иловой грязи имеет следующие компоненты (процент на сухое вещество): растворенные соли - 6,67-15,44 \%; гипс $\left(\mathrm{CaSO}_{4}\right)-0,23-1,71 \%$; карбонат кальция $\left(\mathrm{CaSO}_{3}\right)$ - 7,31$11,23 \%$; карбонат магния $\left(\mathrm{MgCO}_{3}\right)-1,86-12,61 \%$; сульфид железа $(\mathrm{FeS})$, в т.ч. $\mathrm{H}_{2} \mathrm{~S}-0,9-1,96 \%$; продукты разрушения $\mathrm{HCl}$ в т.ч. $\mathrm{SiO}_{2}, \mathrm{Fe}_{2} \mathrm{O}_{3}, \mathrm{Al}_{2} \mathrm{O}_{3}-5,55-6,85$ \%. Объект исследования. Объектом исследований явились куры-несушки. Материалы и методы. На подопытной птице гибридного кросса «Hysex Brown» проводили опыт на территории ФГБОУ ВО Волгоградский ГАУ в НИЦ безопасности и эффективности кормов и добавок. Птицу возраста 40 недель распределяли в три 
подопытные группы (контрольная и две опытные). Опыт длился 140 дней. Результаты и выводы. При включении различных доз органоминеральной добавки, 4 и 5 \%, в состав комбикорма курнесушек, увеличилась яичная продуктивность на 2,84 \% и $1,35 \%$. Стоит отметить, что количество яиц, полученных от птицы опытных групп, было больше и относилось к отборной и высшей категории. При введении в рационы кур-несушек органоминеральной добавки экономический эффект составил от 1075,44 рублей до 1696,92 рублей. В ходе проведенных нами исследований установлено: органоминеральная добавка оказала положительное влияние как на показатели зоотехнические, так и экономические. Оптимальность введения органоминеральной добавки в рецептуру комбикорма для подопытной птицы составила 4 \%.

Ключевые слова: куры-несушки, органоминеральные добавки, продуктивность кур-несушек, рачионы кур-несушек, масса яйца кур.

Цитирование. Шкаленко В. В., Карапетян А.К., Баксарова А. А., Букаева Ю. Г. Эффективность использования кормовой добавки в рецептуре комбикормов сельскохозяйственной птиц. Известия НВ АУК. 2021. 2(62). 298-305.DOI: 10.32786/2071-9485-2021-02-31.

Авторский вклад. В данном эксперименте все авторы принимали участие в планировании, выполнении, а также анализе полученных результатов исследований. Представленный вариант статьи одобрен всеми авторами.

Конфликт интересов. О конфликте интересов авторы не заявляли.

Введение. Птицеводство на сегодняшний день является одной из ведущих, интенсивно развивающихся специфических отраслей агропромышленного комплекса РФ [2]. Развитие отрасли птицеводства осуществляется путем использования высокопродуктивной гибридной птицы, а также прогрессивных ресурсосберегающих технологий и полноценного кормления.

Основным путем повышения продуктивности и резистентности птиц является включение в рацион нутриентов, в том числе минеральных веществ, являющихся неотъемлемой составляющей в метаболизме.

При несбалансированном или недостаточном минеральном питании птицы значительно снижается продуктивность и резистентность организма, возникают серьезные расстройства метаболизма [5]. Наиболее распространённая причина ухудшения продуктивности и защитных сил организма - недостаточно сбалансированное кормление птиц в условиях интенсификации производства.

Цель исследования - изучить влияние органоминеральной добавки на основе сульфидно-иловой грязи на показатели продуктивности кур-несушек.

Объект исследования. Объектом исследований явились куры-несушки. Перед постановкой опыта на птице нами была изучена сульфидно-иловая грязь.

Сульфидно-иловая грязь - природный комплекс, образованный много веков назад в минеральных слоях водоема путём естественного разложения водных растений и организмов. В ее состав входят вещества, богатые ценными свойствами, которые мы используем в виде органоминеральной добавки. Источником полезной грязи являются озера Астраханской области Ахтубинского района. Она состоит из иловых отложений соленых водоемов.

Органоминеральную добавку на основе иловой грязи можно использовать в промышленных масштабах для абсолютно всех животных и птицы при производстве комбикормов с целью повышения в рационах биологически активных веществ, что в свою очередь позволит увеличить зоотехнические и экономические показатели.

Органоминеральная добавка содержит ряд полезных и уникальных веществ, благодаря которым она обладает исключительными свойствами: адсорбционными, буферными и ионообменными и т.д. Также стоит отметить, что ее можно использовать для профилактики и лечений заболеваний желудочно-кишечного тракта сельскохозяйственных животных и птицы. 
Материалы и методы. Опыт проводился на птице кросса Хайсекс Браун. Птицу подбирали в группы по принципу аналогов. При этом условия как кормления, так и содержания птицы были идентичными, в соответствии с указаниями ВНИТИП.

Нами были сформированы три аналогичные группы, в каждой из них - по 56 кур. Длительность опыта - 20 недель (таблица 1).

\section{Таблица 1- Схема выполнения опыта}

Table 1 - Scheme of the experiment

\begin{tabular}{|l|c|c|}
\hline \multicolumn{1}{|c|}{ Группа / Group } & $\begin{array}{c}\text { Число кур-несушек в группе, } \\
\text { голов / Number of laying hens } \\
\text { in the group, heads }\end{array}$ & $\begin{array}{c}\text { Специфика кормления подопытных кур / } \\
\text { The specificity of the experimental feeding } \\
\text { chickens }\end{array}$ \\
\hline $\begin{array}{l}\text { Контрльная / } \\
\text { Control }\end{array}$ & 56 & ОР (основной рацион)/ The main diet \\
\hline $\begin{array}{l}\text { I опытная / } \\
\text { I ехреrienced }\end{array}$ & 56 & $\begin{array}{c}\text { ОР (основной рацион) }+4,0 \% \text { органо- } \\
\text { минеральная добавка/ Basic diet }+4,0 \% \\
\text { organic-mineral additive }\end{array}$ \\
\hline $\begin{array}{l}\text { II опытная / } \\
\text { II experienced }\end{array}$ & 56 & $\begin{array}{c}\text { ОР (основной рацион) }+5,0 \% \text { органо- } \\
\text { минеральная добавка/ Basic diet }+5,0 \% \\
\text { organic-mineral additive }\end{array}$ \\
\hline
\end{tabular}

Птица контрольной группы потребляла основной рацион, разработанный в соответствии рекомендациям ФНЦ «ВНИТИП» РАН. Птице опытных групп дополнительно ввели органоминеральную добавку: в рацион I опытной группы - 4,0 \%, II опытной группы - 5,0 \% от массы основного рациона.

Результаты и обсуждение. В результате использования в рационе органоминеральной добавки интенсивность яйценоскости опытных кур несколько превышала в соотнесении с группой контрольной на 2,84 \% - в I опытной и $1,35 \%$ - во II опытной.

При введении в комбикорм подопытной птице органоминеральной добавки удалось увеличить сохранность поголовья на 3,57 \% и 1,79\%.

О влиянии изучаемой органоминеральной добавки на яйценоскость подопытных кур нельзя судить только по валовому количеству снесенных яиц. Немаловажным показателем яичной продуктивности является такой показатель, как «Яичная масса» (таблица 2).

Таблица 2 - Яичная продуктивной подопытной птицы

Table 2 - Egg production of a test bird

\begin{tabular}{|c|c|c|c|}
\hline Показатель / Indicator & $\begin{array}{c}\text { контрольная } \\
\text { группа / } \\
\text { control } \\
\text { group }\end{array}$ & $\begin{array}{c}\text { I- } \\
\text { опытная } \\
\text { группа / } \\
\text { I-pilot } \\
\text { group }\end{array}$ & $\begin{array}{c}\text { II- } \\
\text { опытная } \\
\text { группа / } \\
\text { II-pilot } \\
\text { group }\end{array}$ \\
\hline \multicolumn{4}{|c|}{ Получено яиц, штук / The obtained eggs, pieces } \\
\hline итого от подопытных кур яиц / total from test hens eggs & 6896 & 7119 & 7002 \\
\hline на одну несушку / on the laying hen & 123,14 & 127,13 & 125,04 \\
\hline Масса яйца (средняя), грамм / Average egg weight, gram & 63,21 & 65,09 & 64,78 \\
\hline ено яичной массы, килограмм / Egg mass obtained, kilogram & 435,90 & 463,38 & 453,59 \\
\hline
\end{tabular}

Следует отметить, что максимально было получено яичной массы от кур за время проведения опыта в группе I опытной - 463,38 кг или на 6,3 процента выше по сравнению с контролем. Наше предположение о том, что органоминеральная добавка оказывает позитивное влияние на яичную продуктивность, оказалось верным и оптимальным является включение в рацион подопытных кур-несушек дозы 4 \%. 


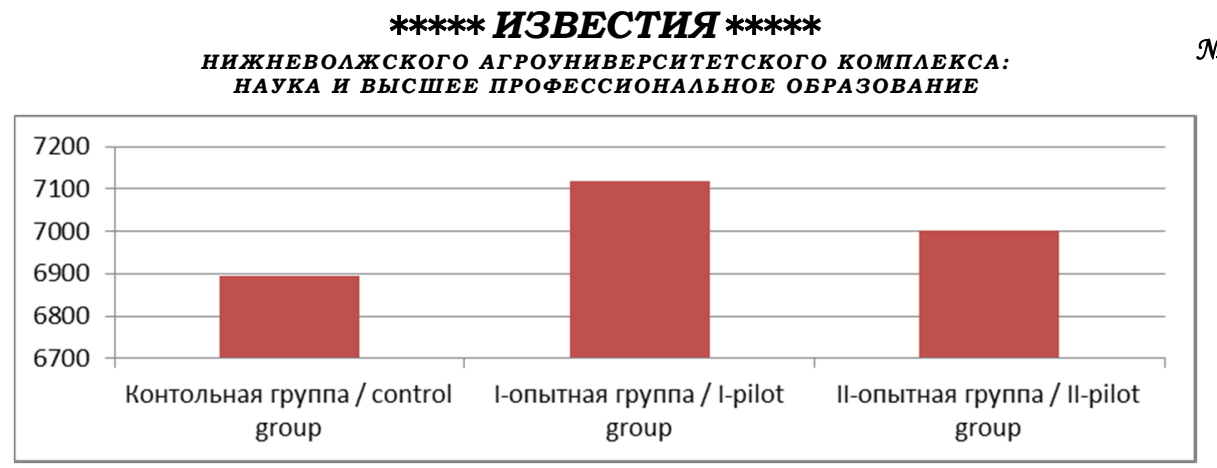

Рисунок 1 - Количество яиц, снесенных подопытными курами за период опыта, шт.

Figure 1 - The number of eggs laid by experimental chickens during the experiment period, pcs.

Установлено, что масса яиц (средняя) в группе кур I опытной прослеживалась выше 65 г и соответствовала отборной категории (CO), что непосредственно оказало влияние на их реализационную стоимость.

Важным зоотехническим показателем является «Затраты кормов на один килограмм яичной массы», который в группах кур контрольной - 2,09 кг, I опытной - 2,04 кг, II опытной - 2,11 кг. Показатель «Затраты кормов на десять яиц» у кур в контроле был на уровне 1,32 кг, в I опытной группе -1,33 кг, во II опытной - 1,36 кг.

Таблица 3 - Потребность кормов

Table 3 - Feed requirements

\begin{tabular}{|c|c|c|c|}
\hline Показатель / Indicator & $\begin{array}{c}\text { контрольная } \\
\text { группа / } \\
\text { control group }\end{array}$ & $\begin{array}{l}\text { I опытная } \\
\text { группа / } \\
\text { I pilot group }\end{array}$ & $\begin{array}{l}\text { II опытная } \\
\text { группа / } \\
\text { I pilot group }\end{array}$ \\
\hline $\begin{array}{r}\text { Затраты корма, килограмм: всего / The cost of } \\
\text { feed, kilogram: all }\end{array}$ & 909,44 & 945,82 & 954,91 \\
\hline $\begin{array}{r}\text { на один килограмм яичной массы / per } 1 \\
\text { kilogram of egg mass }\end{array}$ & 2,09 & 2,04 & 2,11 \\
\hline на десять яиц / for 10 eggs & 1,32 & 1,33 & 1,36 \\
\hline
\end{tabular}

Таблица 4 - Экономическая результативность ввода органоминеральной добавки в рацион кур-несушек

Table 4 - Economic efficiency of the introduction of organomineral supplements in the diet of laying hens

\begin{tabular}{|c|c|c|c|}
\hline Показатель / Indicator & $\begin{array}{l}\text { контрольная } \\
\text { группа / con- } \\
\text { trol group }\end{array}$ & $\begin{array}{c}\text { I опытная } \\
\text { группа / } \\
\text { I pilot } \\
\text { group }\end{array}$ & $\begin{array}{c}\text { II опытная } \\
\text { группа / } \\
\text { I pilot } \\
\text { group }\end{array}$ \\
\hline Количество голов, шт. / Number of heads, pcs & 56 & 56 & 56 \\
\hline $\begin{array}{l}\text { Валовое производство яиц, шт. / } \\
\text { The total production of eggs, PCs. }\end{array}$ & 6896 & 7119 & 7002 \\
\hline Расход комбикормов, кг / Feed consumption, kg & 909,44 & 945,82 & 954,91 \\
\hline $\begin{array}{l}\text { Стоимость израсходованных кормов, руб./ The } \\
\text { cost of the food consumed, RUB }\end{array}$ & 12732,16 & 12986,80 & 13050,46 \\
\hline $\begin{array}{l}\text { Средняя реализационная стоимости } 1000 \text { шт. яиц. } \\
\text { руб. / The average selling price of } 1000 \text { eggs. rub. }\end{array}$ & 4230 & 4340 & 4320 \\
\hline Валовый доход, руб. / Gross income, RUB & 29194,91 & 30891,83 & 30270,35 \\
\hline $\begin{array}{l}\text { Экономический эффект за счет использования ор- } \\
\text { ганоминеральной добавки, руб. / Economic effect } \\
\text { due to the use of organomineral additives, RUB }\end{array}$ & & 1696,92 & 1075,44 \\
\hline
\end{tabular}


По результатам проведённого научно-хозяйственного опыта было рассчитано количество использованных кормов, в т.ч. органоминеральной добавки, а также был рассчитан валовый доход. Необходимо подчеркнуть, что сохранность поголовья подопытной птицы увеличилась в группах опытных на 3,57 \% и 1,79 \% по сравнению с контролем.

За счет введения органоминеральной добавки в комбикорм подопытных кур групп опытных экономический эффект варьировал в пределах от 1075,44 рублей до 1696,92 рублей.

Выводы. Исходя из вышепредставленных данных по изучению воздействия органоминеральной добавки на зоотехнические и эконмические показатели кур-несушек можно сделать следующие выводы:

- ввод 4 и 5 \% органоминеральной добавки в комбикорм кур-несушек привел к повышению яйценоскости за период опыта на 2,84 \% и 1,35 \%;

- увеличилась масса яйца на 1,88 г и 1,57 г, что позволило увеличить дополнительную прибыль при их реализации; экономический эффект увеличился на 1075,441696,92 руб.;

- при использовании добавки в комбикормах для кур-несушек удалось увеличить сохранность поголовья на $3,57 \%$ и 1,79 \%.

Таким образом, использование органоминеральной добавки положительно сказалось как на зоотехнических показателях, так и на экономических. Наиболее оптимальный процент ввода органоминеральной добавки в рецептуру комбикормов для птицы составляет 4 \%.

\section{Библиографический список}

1. Гамко Л. Н., Менякина А. Г., Карпухин В. А. Фармакологические аспекты применение подкислителей воды при выращивании цыплят-бройлеров // Вестник Брянской государственной сельскохозяйственной академии. 2020. № 4 (80). С. 24-30.

2. Данилова Н. В., Лаврентьев А. Ю. Ферменты для повышения продуктивного действия комбикормов // Труды Кубанского государственного аграрного университета. 2017. № 68. С. 145-149.

3. Использование в рационах кур-несушек кормовой добавки «Нутовит» / О. Д. Будтуева, М. В. Струк, И. Г. Плешакова, Д. В. Плешаков // Известия Нижневолжского агроуниверситетского комплекса: Наука и высшее профессиональное образование. 2018. № 1 (49). С. 237-243.

4. Использование различных источников калия при выращивании цыплят-бройлеров / Е. Н. Андрианова, И. А. Егоров, Е. Н. Григорьева, М. Ю. Братчиков, П. А. Кебец // Птица и птицепродукты. 2020. № 1. С. 22-25.

5. Николаев С. И., Струк А. Н., Найдова А. Г. Биологически активная добавка «Эльтон» в кормлении кур-несушек Хайсекс коричневый // Известия Нижневолжского агроуниверситетского комплекса: наука и высшее профессиональное образование. 2017. № 3. (47). С. 136-141.

6. Cerrate S., Corzo A. Lysine and Energy Trends in Feeding Modern Commercial Broilers // International Journal of Poultry Science. 2019. V. 18. N. 1. P. 28-38.

7. Effect of different protein ingredients on performance, egg quality, organ health, and jejunum morphology of laying hens / X. C. Wang, H. J. Zhang, H. Wang, H. Y. Yue, J. Wang, S. G. Wu, G. H. Qi // Poult Sci. 2017. V. 96, I. 5. P. 1316-1324.

8. Faure M., Chone F., Metraux C. Treonine utilization for synthesis of acute phase proteins, intestinal proteins, and mucins is increased during sepsis in rats // XI International Symposium on Digestive Physiology of Pigs. 2017. V. 137. P. 1808-1807.

9. Lei X. J., Lee K. Y., Kim I. H. Performance, egg quality, nutrient digestibility, and excreta microbiota shedding in laying hens fed corn-soybean-meal-wheat-based diets supplemented with xylanase // Poult Sci. 2018. V. 97. I. 6. P. 2071-2077.

10. Merkley L. W. The effect of sodium fluoride on egg production, egg quality and bone strength of caged layers // Poultry Science. 2018. Vol. 4. P. 771-776. 
11. The effects of diets supplemented with phytase on the productive performance, biochemical and morphological blood indices in broilers and layers of broiler preparental lines / I. A. Egorov, V. G. Vertiprakhov, T. N. Lenkova, V. A. Manukyan, T. A. Egorova, A. A. Grozina // Bioscience Research. 2020. V. 17. № 4. P. 2465-2471.

Conclusions. Based on the above data on the study of the impact of organomineral additives on the zootechnical and economic indicators of laying hens, the following conclusions can be drawn:

- enter 4 and $5 \%$ of organic additives in the feed of laying hens resulted in higher egg production during the period of the experience of $2.84 \%$ and $1.35 \%$.

- increased egg weight by $1.88 \mathrm{~g}$ and $1.57 \mathrm{~g}$, which allowed for additional profit when selling them. The economic effect increased by 1075.44-1696.92 rubles.

- when using the additive in compound feeds for laying hens, it was possible to increase the safety of livestock by $3.57 \%$ and $1.79 \%$.

Thus, the use of organomineral additives had a positive effect on both zootechnical indicators and economic ones. The most optimal percentage of the introduction of organomineral additives in the formula of mixed feed for poultry is $4 \%$.

\section{Reference}

1. Gamco L. N., Manakin A. G., Karpukhin V. A. Pharmacological aspects of the application of acidifying agents to the water in growing broiler chickens // Bulletin of the Bryansk state agricultural Academy. 2020. № 4 (80). P. 24-30.

2. Danilova N. V., Lavrentiev A. Yu. Ferments for increasing the productive effect of compound feeds // Trudy Kubanskogo gosudarstvennogo agrarnogo universiteta. 2017. No. 68. P. 145-149.

3. Use in the diets of laying hens feed additives "Notovich" / O. D. Batueva, M. V. Struk, I. G. Pleshakov, D. V. Pleshakov // Proceedings of the XVIII agrouniversity complex: Science and higher professional education. 2018. № 1 (49). P. 237-243.

4. The Use of different sources of potassium in growing broiler chickens / E. N. Andrianov, I. A. Egorov, E. N. Grigoriev, M. Y. Bratchikov, P. A. Quebec // Poultry and poultry products. 2020. No. 1. P. 22-25.

5. Nikolaev S. I., Struk A. N., Naidova A. G. Biologically active additive "Elton" in the feeding of laying hens Haysex brown // Proceedings of the XVIII agrouniversity complex: science and higher professional education. 2017. No. 3 (47). P. 136-141.

6. Cerrate S., Corzo A. Lysine and Energy Trends in Feeding Modern Commercial Broilers // International Journal of Poultry Science. 2019. V. 18. N. 1. P. 28-38.

7. Effect of different protein ingredients on performance, egg quality, organ health, and jejunum morphology of laying hens / X. C. Wang, H. J. Zhang, H. Wang, H. Y. Yue, J. Wang, S. G. Wu, G. H. Qi // Poult Sci. 2017. V. 96, I. 5. P. 1316-1324.

8. Faure M., Chone F., Metraux C. Treonine utilization for synthesis of acute phase proteins, intestinal proteins, and mucins is increased during sepsis in rats // XI International Symposium on Digestive Physiology of Pigs. 2017. V. 137. P. 1808-1807.

9. Lei X. J., Lee K. Y., Kim I. H. Performance, egg quality, nutrient digestibility, and excreta microbiota shedding in laying hens fed corn-soybean-meal-wheat-based diets supplemented with xylanase // Poult Sci. 2018. V. 97. I. 6. P. 2071-2077.

10. Merkley L. W. The effect of sodium fluoride on egg production, egg quality and bone strength of caged layers // Poultry Science. 2018. Vol. 4. P. 771-776.

11. The effects of diets supplemented with phytase on the productive performance, biochemical and morphological blood indices in broilers and layers of broiler preparental lines / I. A. Egorov, V. G. Vertiprakhov, T. N. Lenkova, V. A. Manukyan, T. A. Egorova, A. A. Grozina // Bioscience Research. 2020. V. 17. № 4. P. 2465-2471.

\section{Author information}

Vera Vladimirovna Shkalenko, Professor of the Department "Feeding and Breeding of Farm Animals", Volgograd State Agrarian University (26, Universitetskiy Ave., Volgograd, 400002, Russian Federation), Doctor of Biological Sciences. ORCID: 0000-0002-1627-4597 vera.shkalenko@mail.ru 
Angela Keropovna Karapetyan, Associate Professor of the Department "Feeding and Breeding of Farm Animals" of the Volgograd State Agrarian University (26, Universitetskiy Ave., Volgograd, 400002, Russian Federation), Candidate of Agricultural Sciences,

ORCID: https://orcid.org/0000-0003-2298-0604 a.k.karapetyan@bk.ru

Anastasia Anatolyevna Baksarova, Lecturer of the Department "Feeding and Breeding of Farm Animals" of the Volgograd State Agrarian University (26, Universitetskiy Ave., Volgograd, 400002, Russian Federation), ORCID: https://orcid.org/0000-0001-9235-5084 aa.alseitova@gmail.com

Yulia Grigorevna Bukaeva, Senior Lecturer of the Department of Obstetrics and Therapy,

Volgograd State Agrarian University (Russia, 400002, Volgograd, pr. 26 Universitetskiy street)

ORCID: https://orcid.org/0000-0002-3560-3675 shabasheva.yuliya@mail.ru

\section{Информация об авторах}

Шкаленко Вера Владимировна, профессор кафедры «Кормление и разведение сельскохозяйственных животных» Волгоградского государственного аграрного университета (РФ, 400002, г. Волгоград, пр. Университетский, д.26), доктор биологических наук

ORCID: 0000-0002-1627-4597 vera.shkalenko@mail.ru

Карапетян Анжела Кероповна, доцент кафедры «Кормление и разведение сельскохозяйственных животных» Волгоградского государственного аграрного университета (РФ, 400002, г. Волгоград, пр. Университетский, д.26), кандидат сельскохозяйственных наук,

ORCID: https://orcid.org/0000-0003-2298-0604 a.k.karapetyan@bk.ru

Баксарова Анастасия Анатольевна, преподаватель кафедры «Кормление и разведение сельскохозяйственных животных» Волгоградского государственного аграрного университета (РФ, 400002, г. Волгоград, пр. Университетский, д.26),

ORCID: https://orcid.org/0000-0001-9235-5084 aa.alseitova@gmail.com

Букаева Юлия Григорьевна, старший преподаватель кафедры «Акушерство и терапия»

Волгоградского государственного аграрного университета (РФ, 400002, г. Волгоград, пр-т Университетский, д. 26).

ORCID: https://orcid.org/0000-0002-3560-3675 shabasheva.yuliya@mail.ru 